\title{
FABRICATION AND CHARACTERIZATION OF COPPER GRAPHITE COMPOSITE MATERIAL
}

\author{
GYANENDRA SINGH $^{\mathbf{1}}$, AJITANSHU VEDRTNAM ${ }^{2}$ \& SHIKHAR GUPTA $^{\mathbf{3}}$ \\ ${ }^{1,2}$ Assistant Professor, Department of Mechanical Engineering, Invertis University, Bareilly, India \\ ${ }^{3}$ M.Tech Student, Department of Mechanical Engineering, Invertis University, Bareilly, India
}

\begin{abstract}
Metal matrix composites have superior properties and performance in comparison to the pure metals that justifies their added cost. The present work includes fabrication of metal matrix composite having copper as a base metal and Graphite as the reinforcement. The mechanical testing of the fabricated composite is performed and the mechanical properties are compared with the properties of pure Copper. Mechanical properties of the fabricated composite were found superior to the pure metal.

KEYWORDS: Composite Material, Copper, Graphite \& Metal Matrix Composite
\end{abstract}

Received: Jul 11, 2017; Accepted: Jul 27, 2017; Published: Aug 01, 2017; Paper Id.: IJMPERDAUG201730

\section{INTRODUCTION}

Composite materials have light weight and superior properties when compared to the pure metal [1]. The use of Copper composite is quite common in structural applications, transportation and power sector. The modern technology requires materials with lighter weight, higher strength and superior mechanical properties. Copper metal matrix based composite material comprises high tensile strength, high melting temperature, light weight and good wear resistance [2].

In the present work the Copper composite was prepared by the casting. Different compositions of the graphite were selected with the Copper. Mechanical testing of the prepared sample was performed and a comparison of the result is also presented.

\section{SAMPLE PREPARATION}

The simplest and most commercially used technique is the casting method. Casting is usually liquid reinforcement contact, which can cause considerable interface reaction. One of the major difficulty is the cost of production in the fabrication of particulate metal matrix composites. Casting is to be considered as one of the cheapest technology available for the fabrication of such composites. In 1968, S Ray introduced casting of metal matrix composites, by introducing alumina particles into Copper melt by stirring molten Copper alloys containing ceramic powders. In casting, mechanical stirring in the furnace is regarded to be the key element. Despite of the technical challenges like achieving uniform dispersion of reinforcement within the matrix, casting is effective way of fabricating such composites. However, improper distribution may affects directly on the properties of the composite material. In the present research, Copper matrix alloy with Silicon Carbide and Graphite reinforcements was fabricated using casting. Such low cost fabrication will enable Copper matrix composite (CMC) to move forward aerospace and defense applications to, CMCs higher volume applications. The Table 1 reflects the 
compositions of the samples prepared in the present work. The process of casting, operating parameters and processing and preparation of $\mathrm{CMC}$ material using $\mathrm{Cu}$ as matrix alloy and reinforcement Graphite have been fabricated by varying weight fractions. Among all well-established metal matrix composite fabrication methods, casting is most economical. Casting is currently the most celebrated commercial method of producing copper based composites. The major advantages are simplicity, litheness and applicability to large quantity production. It is also striking because, in the principle of operation, it allows a conventional metal processing route to be used, and hence minimizes the final cost of the product.

Three types sample of cooper graphite composite material were made through casting process. Firstly, there are mixing of powder of cooper \& graphite was performed. Each sample has weight of $200 \mathrm{gm}$. Later material was melted in the Furness at temperatures of $1190 \mathrm{C}$ to $1350 \mathrm{C}$. Figure 1 shows the photograph of fabricated samples.

Table 1: Composition-Time -Temperature Required for Fabricating the Samples

\begin{tabular}{|l|c|c|}
\hline \multicolumn{1}{|c|}{ Composition } & Temperature & Time \\
\hline Copper 98 \%-graphite 2\% & $1190 \mathrm{C}$ & $\mathbf{5 8 ~ m i n}$ \\
\hline Copper 95 \% -graphite 5\% & $1250 \mathrm{C}$ & $\mathbf{1 h r 1 0 m i n}$ \\
\hline Copper 90 \%-graphite 10\% & $1350 \mathrm{C}$ & $\mathbf{1 h r 4 5 m i n}$. \\
\hline
\end{tabular}

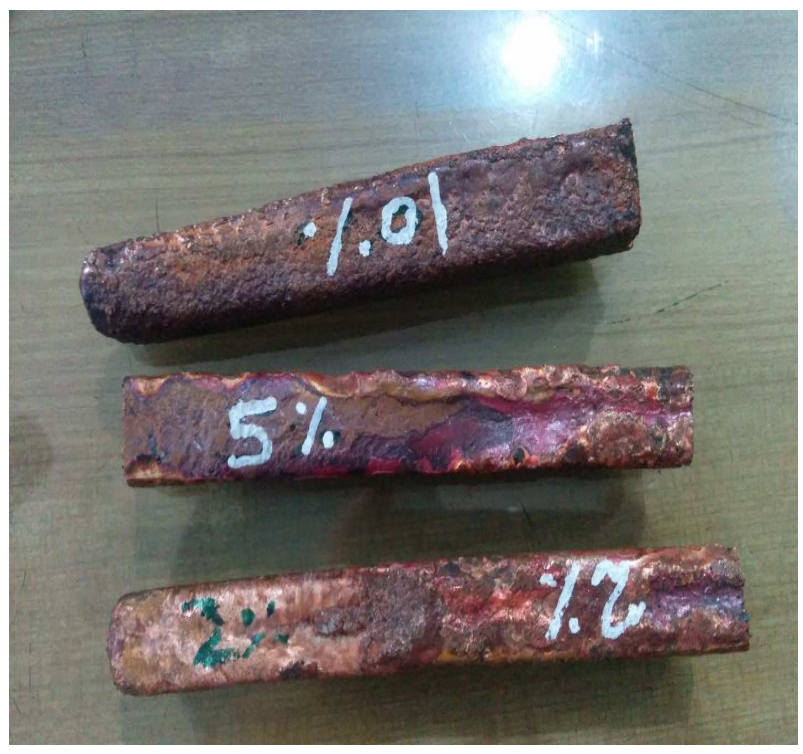

Figure 1: Sample of Cu- Gr Composite Material

\section{Mechanical Testing and Results}

Table 2 shows the results of hardness test of fabricated composite. It clearly indicates that increasing the graphite in copper increases the hardness of the composite. However, the uniformity of graphite in $\mathrm{Cu}$ was not achieved it more than $10 \%$ graphite in $\mathrm{Cu}$ was mixed. The hardness of the fabricated composite varies from 40 to $75 \mathrm{BHN}$. But addition of graphite to copper also migrate the behavior of copper towards brittleness, so an optimization is required as per the application targeted.

Table 2: Hardness Test Results

\begin{tabular}{|l|c|}
\hline Composition of Graphite in Sample & Brinell Hardness \\
\hline Copper $98 \%$-graphite $2 \%$ & 40 BHN \\
\hline Copper $95 \%$-graphite $5 \%$ & 45 BHN \\
\hline Copper $90 \%$-graphite $10 \%$ & 75 BHN \\
\hline
\end{tabular}




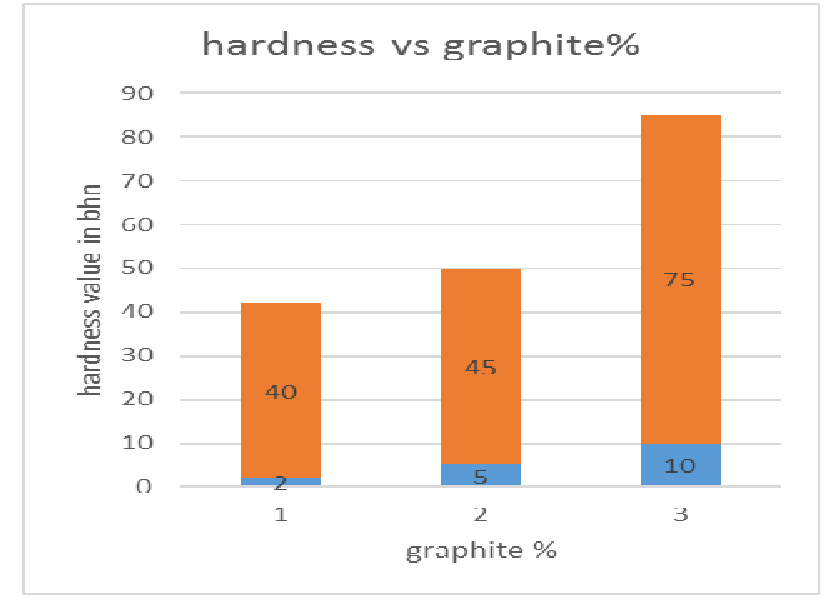

Figure 2: Hardness vs Graphite \%

\section{RESULTS}

Figure 2 represents the variation between hardness \& graphite $\%$ in copper matrix. When the graphite \% increases in copper than we see that the hardness value of composite material increases the strength of the material. When the graphite $2 \%$-copper $98 \%$ the hardness value $40 \mathrm{BHN} \&$ graphite $5 \%$ - copper $95 \%$ the hardness value 45 BHN \& graphite $10 \%$ - copper $90 \%$ the hardness value $75 \mathrm{BHN}$ at $\%$ of graphite between $2 \& 5 \%$ there is hardness increase only $5 \mathrm{BHN}$, but when the percentage of graphite increases up to $10 \%$ the hardness increases up to $75 \mathrm{BHN}$ in the future work research we increases the $\%$ of graphite between 15 to $19 \%$ compare the value.

\section{Tensile Testing}

Table 3 shows the results of tensile test of fabricated composite. It clearly indicates that increasing the graphite in copper increases the tensile strength of the composite. The tensile strength of the fabricated composite varies from 40 to 75 BHN.

Table 3

\begin{tabular}{|l|c|}
\hline Composition of Graphite in Sample & Tensile Strength (MPa) \\
\hline Copper $98 \%$-graphite $2 \%$ & $\mathbf{1 5 9 . 1 1} \mathrm{MPa}$ \\
\hline Copper $95 \%$-graphite $5 \%$ & $\mathbf{1 7 1 . 1 1} \mathrm{MPa}$ \\
\hline Copper $90 \%$-graphite $10 \%$ & $\mathbf{1 8 3 . 0 4} \mathrm{MPa}$ \\
\hline
\end{tabular}

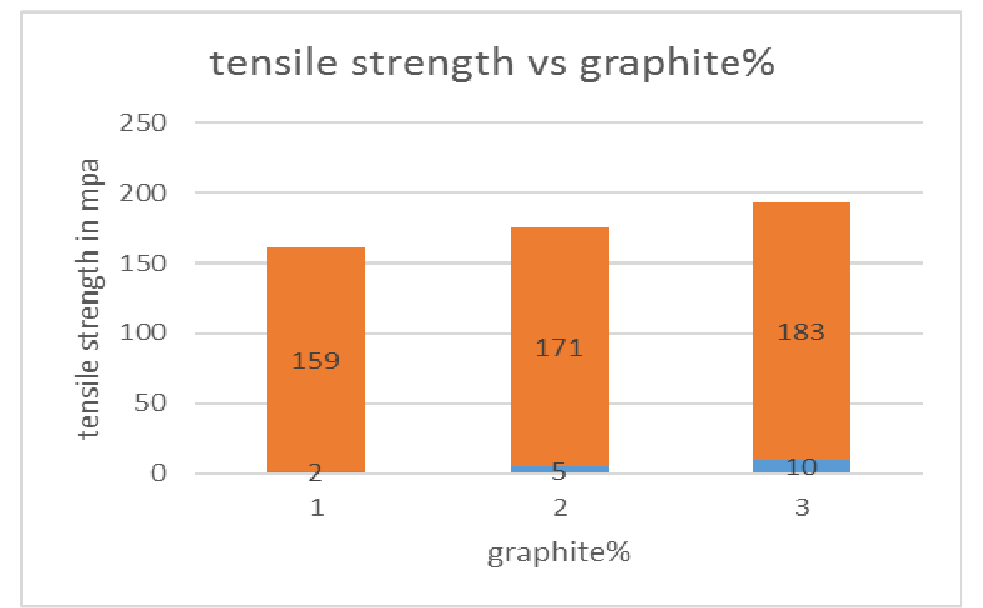

Figure 3: Tensile Strength Vs Graphite \% 


\section{RESULTS}

In tensile testing copper-graphite composite material in above graph When increasing the \% of graphite the tensile strength increasing, from the above graph we can say that copper98\% graphite2\% tensile strength is 159 mpa,copper95\%graphite $5 \%$ the tensile strength increasing to $171 \mathrm{mpa}$,copper $90 \%$-graphite $10 \%$ the tensile strength increasing to $183 \mathrm{mpa} . \mathrm{so}$ it shows that as increasing graphite \% the tensile strength increasing. for future scope we will research about highest increasing tensile strength up to $350 \mathrm{mpa}$ to increasing the graphite $\%$ combined with another material.

\section{CONCLUSIONS}

In this paper, we have fabricated $\mathrm{Cu}-\mathrm{Gr}$ metal matrix composite by casting route and analyze its fabrication by casting Process and different mechanical properties like tensile and hardness. And we have examined that tensile strength increases as weight $\%$ of graphite increases and hardness increase as weight $\%$ of graphite increases.

\section{REFERENCES}

1. Raj Kumar, Vol. 28, part 1, Microwave sintering of copper-graphite composites, journal of processing Technology 209 (2009) $5601-5605$.

2. Yang, Huijun, Luo, Ruiying, Han, Suyi, C G Kang et al. Li, Midan, Effect of the ratio graphite/pitch coke on the Mechanical and tribological properties of copper-carbon composites, Wear 268 (2010) 1337-1341.

3. Silvain, J.F., Petitcorps, Y. Le, J. Zhang et al. Sellier, E., Bonniau, P. and Heim, V., Elastic moduli, thermal expansion and Microstructure of copper-matrix composite Reinforced by continuous graphite fibres, Composites, 25, 7(1994) 570-574.

4. Ma, Wenlin, Jinjun, Lu, Effect of surface texture on transfer layer formation and tribological behavior of copper-graphite composite, Wear 270(2011) 218-229.

5. Zhao, Heijun, Liu, Lei, Wu, Yating, Hu, Wenbin, Investigation on wear and corrosion behavior of Cu-graphite composites prepared by electroforming, Composites Science and Technology 67 (2007) 1210- 1217.

6. S. Suresh, N. Shenbaga Vinayaga Moorthi, S.C. Vettivel, N. Selvakumar; "Process development in stir Casting and investigation on microstructures and wear behavior of TiB2 on Al6061 MMC”; Materials and Design 59 by elsevier (2014), 383-396.

7. Dorfman, Simon, Fuks, David, Stability of copper segregations on copper/carbon metalmatrix Composite interfaces under alloying, Composites Science and Technology 57 (1997) 1065-1069.

8. F. Shehata, A. Fathy, M. Abdelhameed, S.F. Moustafa, J. Alloys Compd. 476 (2008) 300-305.

9. Moustafa, S.F., El-Badry, S.A., Sanad, A.M., Kieback B., Friction and wear of copper- graphite Composites made with Cucoated and uncoated graphite powder, Wear 253 -(2002) 699-710.

10. C. G. Kang, P. K. Rohatgi, "Transient Thermal Analysis of Solidification in a Centrifugal Casting for Composite Materials containing Particle Segregation”, Metallurgical and Materials Transactions, 1996, Volume 27, pg277-285.

11. J. Zhang, R.J. Perez, E.J. Lavernia, "Effect of SiC and graphite particulates on the damping behavior of metal matrix composites", Volume 42, Issue 2, pp 395-409, February 1994.

12. M. L. Ted Guo, Chi. -Y. A. Tsao, "Tribological behavior of self-lubricating copper/SiC/graphite hybrid composites synthesized by the semi-solid powder-densification method", Volume_60_Issue 1, pp 65-74, January 2000.

13. R.F.Cooper. K.Chyung, "Structure and chemistry of fibre-matrix interfaces in silicon carbide fibrereinforced glass-ceramic 
composites: an electron microscopy study”, Volume 22, Number 9, pp 3148-3160. 1987

14. L.C. Davis, B.E.Artz, "Thermal Conductivity of metal matrix composites", Journal of Applied Physics, Vol. 77, pp 4954-4960, July 2009.

15. S Cem Okumus, Sredar Aslan et al, "Thermal Expansion and Thermal Conductivity Behaviors of AlSi/SiC/graphite Hybrid Metal Matrix Composites (MMCs)”, Volume 18, No 4, 2012.

16. Na Chen, Zhang et al, "Effect of Thermal cycling on the expansion behaviour of Al/SiC composites", Journal of Materials Processing Technology, pp 1471-1476, 2009.

17. S.F. Mustafa, Z. Abdel-Hamid, A.M. Abd-Elhay "Copper matrix Sic and Al2O3 particulate composites by powder metallurgy technique” Materials Letters 53 (2002) 244-249 6. Da Hai He, Rafael Manory “A novel electrical contact material with improved self-lubrication for railway current collectors" Wear 249 (2001) 626-636.

18. S.F. Mustafa, S.A. El-Badry, A.M. Sanad, B. Kieback "Friction and wear of copper-graphite composites made with Cucoated and uncoated graphite powders" Wear 253 (2002) 699-710.

19. V.V. Rao, M.V. Krishna Murthy, J. Nagaraju "Thermal conductivity and thermal contact conductance studies on Al2O3/AlAlN metal matrix composite" Composites Science and Technology 64 (2004) 2459-2462.

20. X.C. Ma, G.Q. He, D.H. He, C.S. Chen, Z.F. Hu, "Sliding wear behavior of copper-graphite composite material for use in maglev transportation system” Wear 265 (2008) 1087-1092.

21. K. H. W. Seah, S. C. Sharma and B. M. Girish "Mechanical properties of cast ZA=27/graphite particulate composites" SO261-3069(96)00001-5

22. S.F. Mustafa,Z. Abdel-Hamid, A.M. Abd-Elhay "Copper matrix Sic and Al2O3 particulate composites by powder metallurgy technique” Materials Letters 53 (2002) 244-249

23. C.S. Ramesh, R. Noor Ahmed, M.A. Mujeebu, M.Z. Abdullah "Development and performance analysis of novel cast copperSic-Gr hybrid composites" Materials and Design 30 (2009) 1957-1965

24. K. Raj Kumar, S. Aravindan "Microwave sintering of copper-graphite composites" Journal of Materials Processing Technology 209 (2009) 5601-5605.

25. C.S. Ramesh, R. Keshavamurthy, B.H. Channabasappa, S. Pramod "Friction and wearbehaviorofNi-PcoatedSi3N4 reinforced Al6061composites" Tribology International 43 (2010) 623-634.

26. K. Raj Kumar, S. Aravindan "Tribological performance of microwave sintered copper-TiC-graphite hybrid composites" Tribology International 44 (2011) 347-358

27. S. K. Ghosh, Partha Saha "Crack and wear behavior of SiC particulate reinforced copper based metal matrix composite fabricated by direct metal laser sintering process" Materials and Design 32 (2011) 139-145

28. A. Fathy, F. Shehata, M. Abdelhameed, M. Elmahdy "Compressive and wear resistance of nanometric alumina reinforced copper matrix composites" Materials and Design 36 (2012) 100-107 
